\title{
LA PROPIEDAD DE LAS AGUAS EN EL SEÑORÍO SOLARIEGO DE AGUAS DE BUSOT
}

\author{
Ana Rosa Candela Hidalgo
}

\begin{abstract}
RESUMEN
La enfiteusis se constituye como el régimen de tenencia predominante en el señorío solariego de Aguas de Busot. Las aguas, procedentes de manantiales o captaciones subterráneas, habían sido cedidas, desde el siglo XVII, a los enfiteutas por los señores del lugar, al margen de una parte de las mismas reservada en plena propiedad. Este artículo recoge las características de esa forma de tenencia, así como el proceso de compras del dominio útil seguido por los titulares del dominio directo durante la segunda mitad del siglo XIX; gracias al cual, y a pesar del nuevo marco sociopolítico y legal creado tras la abolición del régimen señorial, conseguirán recuperar la plena propiedad de parte del patrimonio antiguamente establecido a través de la consolidación de dominios.
\end{abstract}

\begin{abstract}
Emphyteusis was the prevailing tenure system in the demesne fief named Aguas de Busot. Underground or spring waters, had been handed over, since the seventeenth century, by the owners of the village to the tenants. A part of this waters were reserved by the feudal lord for his own use. This study includes the analysis of the tenure form characteristics as well as the process of the useful ownership purchases carried out by the propietor of the eminent domain, during the second half of the nineteenth century. Through this process the lord of the manor would get back part of his heritage emphiteutically established, despite the abolition of the seignorial system and the new sociopolitical situation.
\end{abstract}

El término de Aguas de Busot, con una extensión aproximada de 1.860 hectáreas y un carácter relativamente montañoso, se encuentra situado en el sector septentrional de la comarca del Campo de Alicante, en la parte alta del Valle de Busot. La mitad occidental de su término se encuentra enmarcada por las estribaciones meridionales de la sierra del Cabeçó d'Or, y las septentrionales de las sierras de Bonalba y Ballestera.

Ubicada en el extremo oriental de las cordilleras Béticas, y más concretamente en el 
dominio prebético meridional ${ }^{1}$, y constituida por materiales secundarios y terciarios (al margen de los depósitos cuaternarios), calizas, areniscas y margas, la zona presenta como elemento destacado del relieve la sierra del Cabeçó d'Or, anticlinal jurásico de carácter extrusivo, cuyas características litoestratigráficas y tectónicas serán determinantes en la configuración del potencial hídrico de la zona ${ }^{2}$. La abundancia de fuentes y manantiales de agua en este paraje (incluyendo una de características termales) fue puesta de manifiesto por los diferentes cronistas y autores contemporáneos, al tiempo que vinculada a la toponimia del lugar.

Efectivamente, la permeabilidad y la exposición a los procesos de erosión química por disolución de las calizas jurásicas (y cretácicas de los flancos), el diaclasamiento de los materiales y la disposición estratigráfica de los mismos (buzamientos subverticales), han potenciado la actuación de un proceso cárstico en profundidad que ha dado lugar al desarrollo de un carst interno, a la vez que han posibilitado la existencia de un sistema acuífero actualmente sobreexplotado ${ }^{3}$. La disminución del nivel piezométrico del mismo será el causante de la desaparición de las resurgencias que habían proporcionado las aguas necesarias para dotar de riego al término.

La penuria e irregularidad de las precipitaciones conjungada con la intensa evapotranspiración determinada por unos registros térmicos elevados (elementos que definen un ámbito marcado por una notoria aridez), unida a la carencia de cursos fluviales autóctonos importantes, caracterizados por un caudal escaso e irregular, confiere una extraordinaria importancia a los recursos hídricos proporcionados por estas fuentes; recursos que posibilitarán el desarrollo de una cierta actividad agraria con las connotaciones de un regadío deficitario.

Al margen de estas puntualizaciones generales, es necesario aludir al carácter de antiguo señorío solariego de este término. Ubicado en un ámbito caracterizado por la presencia de un importante núcleo realengo rodeado de pequeños señoríos de jurisdicción alfonsina, presenta, como rasgo diferenciador en relación a estos últimos, la carencia de competencias jurisdiccionales del titular del mismo. Este hecho, unido a la tardía adquisición del elemento territorial del señorío (a principios de siglo XVII, con motivo de la venta efectuada por D. Francisco Rocamora, señor de las baronías de Novelda, Mogente y Castillo de la Mola, y de los lugares de la Granja y Agost, a favor de D. Alfonso Martínez de Vera, emparentado con los dueños de Busot y posteriormente heredero del vínculo de los Martínez de Vera) deparará, a tenor del nuevo marco sociopolítico y legal creado en el siglo XIX tras la abolición del régimen señorial, una evolución peculiar del mismo, puesto que los dueños del lugar conseguirán mantener una parte importante del antiguo patrimonio establecido enfitéuticamente, tanto por lo que respecta a la propiedad de la tierra como de las aguas.

\section{Recursos hídricos y características del régimen de tenencia del agua}

Según se desprende de la escritura de venta del lugar de Aguas en 1609, las aguas del paraje eran también propiedad de los titulares del señorío solariego ${ }^{4}$. Procedentes de

1 RODRÍGUEZ ESTRELLA, T.: «Síntesis geológica del prebético de la Provincia de Alicante», Boletín Geológico y Minero, T. LXXXVIII, Madrid, 1977.

2 SÁNCHEZ NAVARRO, T.: Estudio morfoclimático del Cabeçó d'Or. Universidad de Alicante, Alicante, 1991.

3 SÁNCHEZ NAVARRO, T. (1991): Op. Cit., pp. 24 y 95-100.

$4 \ll(\ldots)$ do vendo, concedo actrado seu quasi trado vobis Alfonsio Martínez de Vera militi in Civitate 
fuentes y manantiales $\mathrm{u}$ obtenidas tras la realización de excavaciones (generalmente a expensas de los enfiteutas), eran recogidas en balsas y cedidas en enfiteusis por los Marqueses del Bosch, quienes se reservaban el dominio directo de las mismas y el resto de derechos enfitéuticos (luismo, fadiga, canon, exigencia de autorización señorial para las enajenaciones,...). Una parte de estos recursos eran retenidos por los dueños en plena propiedad, para dotar de riego las fincas de su entera posesión. Durante el siglo XIX, la política de compra de tierra (del dominio útil en unos casos, y la plena propiedad en otros) se vio acompañada por otra similar de compra de agua.

El aprovechamiento de las aguas para riego y, por tanto, el ordenamiento de esta actividad, requieren la implantación de un sistema de distribución y regulación de los caudales hídricos; sistema que, fundamentado en un cómputo horario, cuenta como unidad básica de división con la hora de agua, agrupadas en turnos o tandas de distinta duración según el caudal de la fuente de que se trate (aunque siempre inferiores a 20 días). Es, por tanto, un sistema similar al adoptado en otras áreas provinciales de regadío tradicional, como la huerta de Alicante o el Campo de Elche 5

Al igual que en los ejemplos mencionados, es característica la disociación entre propiedad de la tierra (o dominio útil de la tierra) y propiedad del agua (o dominio útil del agua). $\mathrm{El}$ agua, aunque se transfiere de manera general conjuntamente con la tierra, en bastantes ocasiones es objeto de venta independiente, y de establecimiento por el señor del mismo modo.

Los alumbramientos existentes en el lugar presentan una distinta antigüedad, y en su mayor parte se han agotado a finales del siglo XIX y principios del siglo XX. Así se pone de manifiesto por ejemplo en el Registro de la Propiedad o con motivo de alguna venta. En una inscripción registral del último cuarto del s. XIX, se recoge el testimonio de la inutilización de la Balsa Nueva (situada en las cercanías de los Baños):

«El referido Lorenzo García Yborra declara que en la escritura de fundación de la balsa nueva otorgada en 13 Enero de 1803, ante el Escribano que fue de Alicante D. Pedro Fuentes aparece la siguiente $=$ Cláusula $7^{\mathfrak{a}}=\mathrm{Y}$ últimamente es condición que si se secare en todo la agua que sale de dicha excavación, y no fluyese alguna, quedará nula y de ningún valor ni efecto esta escritura y todos los interesados, como estaban antes de su celebración= En acta notarial otorgada en 6 Noviembre de 1879 por V. Brotons y Beviá se hace constar haberse secado el manantial y dejado de fluir el agua en la Balsa Nueva, y por tanto $=$ «Que por tales motivos, en concepto del que declara, caducaron sus derechos a dicha balsa y agua, pero si algunos pudiera

\footnotetext{
Alicantis (...) heriditates quas ego habeo et possideo intermino dicta Civitatis Alicantis vulgariter nuncupatas Aygues et Baranyes plantatas vineys et arboribus unacum domibus turre heremita et fontibus aqua ineis existentibus et cum omnibus terris cultis et incultis illarum pro ut confrontantur en termino generali jam dicta Civitatis, et cum termino Loci Busot y Cabrafich, et cum termino de Vilajosa y Cabeçó, et cum aliis montibus regiis (...)». ARV. Real Audiencia. Procesos de Madrid, A, Leg. 2.220, n.ำ 312, año 1614, fs. 7-12.

5 ALBEROLA ROMA, A. (1984): Jurisdicción y propiedad de la tierra en Alicante (siglos XVII y XVIII). Ayuntamiento - Universidad de Alicante, Alicante, 1984, pp. 159-193; El pantano de Tibi y el sistema de riegos en la Huerta de Alicante. Instituto Juan Gil-Albert, Alicante, 1984; «Las disponibilidades hídricas en la huerta alicantina: un problema tradicional» en Demanda y Economía del agua en España, Alicante, 1988; COSTA MAS, J.: «La cuestión del agua en un área de tradicional regadío deficitario: Elche», Demanda y..., pp. 379-387; GIL OLCINA, A.: «El regadío en Elche», Estudios Geográficos, Madrid, 1968, XXIX; GOZÁLVEZ PÉREZ, V.: El Bajo Vinalopó. Geografía Agraria. Valencia, 1977, pp. 201-243; LÓPEZ GÓMEZ, A.: «Riegos y cultivos en la Huerta de Alicante. Evolución y estado actual», Estudios geográficos, n. ${ }^{\circ} 45$, Madrid, 1951, pp. 701-771; «Riegos y cultivos en las huertas valencianas», Cuadernos de Geografia, n. 1, Valencia, 1965, pp. 1-23.
} 
tener, los enajena y renuncia por la presente, sin que pueda utilizarlos ni reclamarlos bajo ningún concepto, dejando espeditos los que correspondan al Ylustre Señor, Marques del Bosch» ${ }^{6}$.

En el caso de las aguas en plena propiedad de los Marqueses del Bosque, a pesar de ir transfiriéndose por herencia hasta M..$^{\mathrm{a}}$ Teresa Rojas y Roca de Togores, se pone de manifiesto, de igual modo, la pérdida de valor y el agotamiento de dichas fuentes. Así ocurre, por ejemplo, con 431 horas de agua recibidas por esta última, puesto que, carentes de valor por no existir ya ni las aguas ni las balsas (del Cañar, del Cantal, de los Baños, Nueva, del Ciscar), les fue asignado un valor simbólico de 10 pts. por hora de agua.

La mayor parte de estos manantiales se encontraban situados en las proximidades de los Baños. Las escrituras de establecimiento localizadas han sido muy escasas, por tanto, han resultado de gran ayuda los libros de translaciones de dominio de la Contaduría de Hipotecas. Esta fuente, sin embargo, presenta el inconveniente de la falta de veracidad de las anotaciones registradas por lo que respecta a las declaraciones de cargas, puesto que, como ocurría en el caso de Busot, se hace patente en ella la resistencia de los enfiteutas a reconocer y satisfacer los derechos señoriales. Por este motivo, en relación al agua procedente de una misma balsa, se hace constar tanto la inexistencia de gravámenes, como el desconocimiento de éstos en el caso de que los hubiera o su aceptación y reconocimiento. Las principales fuentes existentes en el término son las siguientes:

\begin{tabular}{|c|c|c|c|}
\hline \multirow{2}{*}{$\begin{array}{l}\text { BALSAS (de) } \\
\text { la Mata }\end{array}$} & \multicolumn{2}{|c|}{ TANDAS } & \multirow{2}{*}{$\begin{array}{l}\text { CARGAS SEÑORIALES } \\
\text { No se expresan/No/Sí }\end{array}$} \\
\hline & 18 & días & \\
\hline el Horno de Vidrio & 16 & días & No \\
\hline el Castelled & & & No \\
\hline los Campellos & 15 & días & No se expresan/No/Sí \\
\hline los Baños & 18,5 & días & No se expresan/No/Sí \\
\hline el Cañar & 15 & días & No se expresan/No/Sí \\
\hline los Yborras & 18 & días & No se expresan/No/Sí \\
\hline Nueva & 16 & días & No se expresan/No/Sí \\
\hline el Cantal del Paller & 15 & días & No/Sí \\
\hline el Ciscar & 16 & días & No/Sí \\
\hline la Alquería & 15 & días & No se expresan \\
\hline $\mathrm{No}=\mathrm{Sin}$ cargas & \multirow{5}{*}{\multicolumn{2}{|c|}{$\begin{array}{lr}\text { FUENTE: } \quad \begin{array}{r}\text { Libro } \\
\text { Regis }\end{array} \\
\text { Elaboración Propia. }\end{array}$}} & ntaduría de Hipotecas. \\
\hline $\mathrm{Si}=$ Con cargas & & & a Propiedad de Jijona. \\
\hline La Mata $=$ La Murta & & & \\
\hline Yborras=Gasparet & & & \\
\hline Cantal P.=Barañes & & & \\
\hline
\end{tabular}

A pesar de la confusión que parece desprenderse del cuadro, no cabe la menor duda de que la mayor parte de las aguas pertenencían al patrimonio de los Marqueses del Bosque (exceptuando aquellas que estuvieran radicadas en terreno realengo), quienes las habían establecido enfitéuticamente a los labradores de Aguas. La cesión en enfiteusis de aguas (tanto las sobrantes - las que se perdían una vez regados los campos o las que circulaban

6 Registro de la Propiedad de Jijona. T. 194, Lib. 11, Fca. 426, f. 26. 
por torrentes y barrancos-, como las captadas de los ríos o las subterráneas), para la puesta en regadío de tierras y la construcción de molinos harineros, o con otros fines meramente especulativos, era una práctica igualmente empleada en el realengo alicantino por el Real Patrimonio?.

Las condiciones de los establecimientos de aguas han sido deducidas del apartado de cargas incluido en las escrituras de venta del dominio útil, dada la práctica inexistencia de este tipo de contratos durante el último cuarto del siglo XVIII y siglo XIX. A los derechos enfitéuticos característicos (luismo $-10 \%$ del precio de venta-, fadiga, obtención de licencia señorial en caso de enajenaciones, ...) se une un canon anuo y de carácter perpetuo impuesto preferentemente en metálico (aunque existen casos en los que el pecho es de otra naturaleza). La cuantía del mismo varía de unos casos a otros, y ha sido imposible establecer un pecho homogéneo por hora de agua, puesto que varía de una balsa a otra e, incluso, en relación a una misma balsa. Hecho que probablemente responda a diferentes períodos de establecimiento, a las condiciones y compensaciones que incluía el contrato enfitéutico originario, o al caudal de las diferentes fuentes. Así por ejemplo, con respecto a la balsa del Cañar, en varias anotaciones de los libros de Contaduría de Hipotecas se declara la sujeción a un canon de 17 maravedíes por hora de agua ${ }^{8}$, mientras que, en una venta realiza en 1854 de 6 horas y 45 minutos de agua procedente de esta misma balsa, se reconocía como gravamen un canon de 10 rs. 2 mrds (más de 50 mrds. por hora de agua), al margen del pecho correspondiente a la parte del censo consignativo de $1.200 \mathrm{~L}$. impuesto sobre la finca de los Arnaus'.

Censos de carácter redimible (consignativos) eran los únicos que en ocasiones gravaban el agua establecida enfitéuticamente, resultado de la imposición del mismo sobre el total de la finca inicialmente cedida. Un ejemplo de ello es el agua procedente de la Balsa de los Yborras (Gasparet). Se ha de señalar, sin embargo, que, con frecuencia, no era detallada la cuantía de los cánones ni en las escrituras recogidas en los protocolos notariales ${ }^{10}$ ni en las anotaciones de la Contaduría de Hipotecas y el Registro de la Propiedad; y, en los casos en que tierra y agua eran vendidas conjuntamente, tanto el precio como el canon mencionados englobaban los específicos de cada uno de los dos bienes objeto de venta.

El agua procedente de otra serie de balsas (balsa del Ciscar o balsa Nueva) había sido gravada con un censo distinto, consistente en 1 vaso de agua por cada día de agua, manteniendo de igual modo el resto de derechos.

La única escritura de establecimiento de aguas localizada es la otorgada por D. Rafael Canicia Vaillo de Llanos en 1803 a un colectivo de labradores residentes en Aguas. En ella, se les concedía licencia para fabricar una balsa, conocida como la balsa Nueva, en el paraje de la Cogolla, en las cercanías de los Baños. La obtención de estas aguas de origen subterráneo, en unos terrenos propiedad de los Marqueses, había exigido la realización de

7 ALBEROLA ROMA, A.: «Los establecimientos de aguas en el Realengo alicantino: Una forma de aplicar el contrato enfitéutico por el Real Patrimonio a fines del siglo XVIII», Revista de Historia Moderna, $\mathrm{n}^{\circ}{ }^{\circ} 3$, Alicante, año 1983, pp. 99-113.

8 Registro de la Propiedad de Jijona. Contaduría de Hipotecas,

Lib. 3. de translaciones de dominio, años 1854 y 1855 .

9 Registro de la Propiedad de Jijona. T. 395, Lib. 22, Fca. 1.421, f. 169; y Contaduría de Hipotecas. Lib. n.o 2 de translaciones de dominio.

10 La escritura de venta de 2 horas de agua de la balsa de los Baños, otorgada el 31-X-1805 por L. García a favor de G. García (ambos labradores y vecinos de Aguas), incluía la licencia señorial, y en ella se reconocían el dominio directo del Marqués del Bosch y la obligación del enfiteuta de respetar y satisfacer los derechos de luismo, fadiga y el resto de los enfitéuticos, aunque no mencionaba explícitamente ningún tipo de canon (ni su cuantía). AHPA. Prot. Not. de F. Sala y Cantó, P. 1.624, año 1805, fs. 130-131 vto. 
las obras de perforación, previa licencia señorial, a expensas de los futuros enfiteutas. Así se pone de manifiesto en el siguiente fragmento de dicha escritura:

«(...) Que como posehedor que es de los vínculos de Martínez de Vera, y como tal Dueño directo del Pago de Aguas Altas, término y jurisdicción de esta referida ciudad por la presente escritura establece, y da Licencia a Gregorio Yborra de Pedro Antonio, Bautista Bernabeu de Bartolomé, Lorenzo Brotons de Lorenzo, Rafael García, Antonio García, Francisco García, y Lorenzo García, hermanos, los siete de exercicio Labradores, moradores en dicho Partido de Aguas Altas, para que puedan fabricar una Balsa en la nominada Partida, y particular de la Cogolla del Camino por arriva para recoxer el Agua que actualmente sale de la excavación nueva que han hecho los referidos siete arriba nombrados, con licencia de su Señoria, de ancho y largo que les paresca suficiente, y pudiendo abrir sanjas para conducir la referida agua a sus tierras, concediendoles tambien dicho Ylustre Señor Marques licencia para fabricar otra Balsa del Camino por abajo en caso nesesario para condusir el agua, que no pueda recoxerse en la antecedente Balsa de arriva, cuyo establesimiento les consede con formal transpaso Cesion de la mencionada agua en favor de los enunciados ...» ${ }^{11}$.

A resultas de las condiciones impuestas en este establecimiento, tanto los costes ocasionados por el alumbramiento de las aguas como por su posterior distribución y almacenamiento recaían en los nuevos enfiteutas, mientras que el Marqués obtenía con ello importantes beneficios sin efectuar ningún desembolso. Efectivamente, los enfiteutas debían llevar a cabo, a sus expensas, las obras iniciales de excavación, y una vez obtenidas las aguas, la construcción de la balsa y las acequias necesarias para su conducción a las tierras. El señor directo, además de lograr la creación de la nueva balsa sin ningún costo, conseguía el dominio directo del agua contenida en dicha balsa y las rentas inherentes a dicho dominio (principalmente las procedentes del luismo o de la solicitud de la licencia señorial en caso de enajenación), junto a la plena propiedad de dos días de agua en cada tanda de 16 días; sin olvidar los beneficios indirectos que dicha agua le reportaría a tenor de la revalorización de las tierras, cuyo dominio directo poseía, ante la posibilidad de introducir el regadío. Por esta razón, el canon enfitéutico impuesto, consistente en un vaso de agua por cada uno de los enfiteutas, no debía resultar demasiado gravoso para el enfiteuta, quien había corrido con todos los gastos de la empresa.

Las condiciones impuestas en dicho establecimiento fueron las siguientes:

- Los enfiteutas han de costear a sus expensas la balsa (o balsas) que se construyera, encargándose igualmente de su reparación y mantenimiento en correctas condiciones, al igual que de las acequias, sin poder solicitar ninguna compensación por ello.

- Se establece una tanda de 16 días para el riego, correspondiendo 2 días a cada uno de los enfiteutas y otros 2 días al señor directo; quien no se verá obligado a participar de los gastos de reparación o mantenimiento.

- Los enfiteutas en caso de enajenación del agua y las tierras deberán obtener la licencia señorial y avisar al señor un mes antes de la venta, para que éste pueda ejercer el derecho de fadiga, puesto que tendrá preferencia en la adquisición de las mismas. En caso contrario caerán en «las penas del enfiteusis» (comiso), careciendo de valor la transacción efectuada.

11 ARV. Bailía, E, n. 405 Apéndice, año 1816, fs. 5-12. 


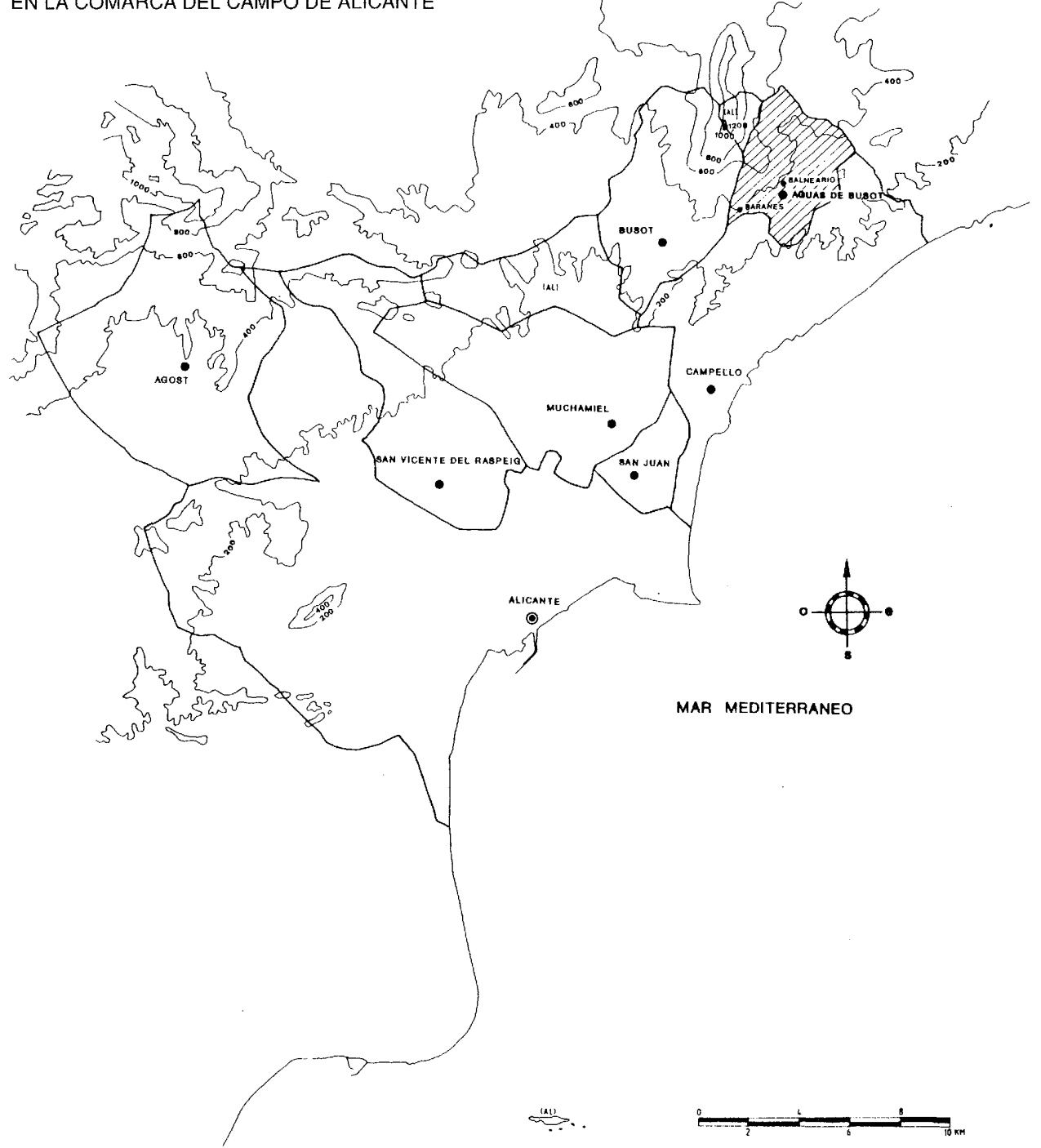

- Se impone un canon o pensión anua de 1 vaso de agua a cada uno de los enfiteutas, quienes están obligados, además, a pagar el luismo en las enajenaciones, a razón del 10\% del precio estipulado.

- La acequia que ha de fabricarse para conducir el agua desde esta balsa hasta la otra de los Baños han de costearla los enfiteutas, sin que ninguno de los propietarios de las tierras por donde circule dicha agua pueda pedirles nada por ello.

- Todos los enfiteutas deben permitir que por sus tierras pasen las conducciones de agua, de modo que todos estén en condiciones de regar sus tierras.

- En caso de secarse la fuente, quedaría anulada la escritura de establecimiento. 
La superficie regada con estas aguas no fue muy elevada, puesto que en 1816 se habían visto beneficiadas 17 tahúllas 1 octava $(2,0567 \mathrm{ha}$.), distribuidas en pequeñas parcelas entre 0,5 y 2,5 tahúllas; pero las 3.200 libras en que fueron valoradas las 384 horas de agua resultantes ${ }^{12}$ (8,33 L./hora de agua) da idea de la importancia de las mismas (aunque esa cuantía es bastante inferior a la que alcanzarán a mediados de siglo tanto las horas de agua procedentes de esa balsa como las de otras balsas).

Sin embargo, estas acciones de los marqueses fueron rechazadas en diversas ocasiones por los procuradores del Real Patrimonio, quienes denunciaban la ilegalidad de tales establecimientos aduciendo para ello el carácter de realengos de los terrenos en los que radicaban las resurgencias, o bien que solamente el Real Patrimonio tenía competencias para establecer aguas subterráneas.

Así sucedía en 1816 en relación al establecimiento de la balsa Nueva, pues, el 26 de abril de ese año, los enfiteutas anteriormente mencionados fueron acusados por el fiscal patrimonial de usurpar tierras y aguas realengas sin solicitar las correspondientes licencias de establecimiento ${ }^{13}$. La Marquesa del Bosch, D. ${ }^{a}$ Catalina Pascual y Vergara, presentó, para contrarrestar dicha acusación, la copia del decreto de la Real Audiencia de Valencia de fecha 12-VII-1816, en el que se la amparaba en el uso y posesión de todas las aguas de los Baños de Busot y del resto de balsas y terrenos del lugar de Aguas:

«se mantiene y ampara, y en caso necesario rehintegra a la Marquesa del Bosque, Condesa de Torrellano, como Administradora de los vienes y rentas de su marido en el uso, gose y Posecion de disponer de las aguas de los Baños de Busot, de su caserío, de las demas aguas, balsas y terrenos de dicho termino, cuya posecion no perturben la Ciudad de Alicante, su Junta de Sanidad, Administrador de la Baylia ni otras personas, ni innoven en cosa alguna, reponiendo qualquiera novedad al estado anterior a ella, baxo la pena de doscientas libras, con reserba a estos para que usen del derecho que entiendan tener para lo contrario en el Juicio Plenario de Poseción o de Propiedad, .... ${ }^{14}$.

El fiscal patrimonial aducía los argumentos anteriormente mencionados, a la vez que criticaba el descuido y desinterés del procurador patrimonial de la Bailía de Alicante que había permitido que ese hecho tuviera lugar hacía trece años. A pesar de sus recomendaciones de exigir a la marquesa la presentación de los títulos de posesión y disfrute de las aguas y la fuente, parece ser que el expediente no prosiguió ${ }^{15}$. Además, los acontecimientos y testimonios posteriores, que siguen reconociendo a los marqueses como los dueños directos de dichas aguas, demuestran la continuidad en éstos de dicha posesión.

Un enfrentamiento similar, esta vez en torno al establecimiento de 4 jornales de tierra en el paraje del Colladet y del agua obtenida tras la realización de una excavación en dicho terreno, tuvo lugar en 1819 entre la Marquesa del Bosch y la ciudad de Alicante; aunque en esta ocasión el proceso fue inverso.

El 16-VI-1819 un grupo de 30 personas (29 labradores y vecinos de Aguas, y un cirujano, vecino de Alicante) solicitaron del Real Patrimonio que les fuera establecido un terreno de unos 4 jornales, que consideraban de realengo, en el que habían excavado y

12 Ibídem, fs. 13-16.

13 ARV. Ibídem, fs. 1-2.

14 Ibídem, fs. 19-19 vto.

15 Ibídem, fs. 19 vto. -20 vto. 
descubierto un pozo a sus expensas; sin que hubiese existido ninguna oposición a la realización de dichas obras, y puesto que reclamaban la propiedad del agua que habían obtenido a sus costas. En el memorial presentado al procurador patrimonial de la Bailía de Alicante se alude a las obras de alumbramiento emprendidas en el Colladet, donde «habían observado de tiempo inmemorial mucha humedad, y brollar a las veces una pequeña fuente en tiempos de abundancia que producía cenagares perjudiciales a la salud pública por cuya razon la Real Junta de Sanidad en cierto año huvo de acordar y acordó abrir cauce y dar salida a las aguas encharcadas que venian entonces á parar a la acequia propia del riego del exponente y demas interesados, quienes ultimamente obligados por la sequedad de la tierra en estos años motivada por la escasez y falta de las lluvias y entendiendose autorizados por el Real Decreto de Su Majestad dado en el mes de Junio de 1816 en favor de la Agricultura e iluminación de Aguas, verificaron la inspeccion del sitio dicho el colladet por medio de un perito hidraúlico y procedieron a sus costas a la cava indicada logrando por esta diligencia hacer brotar una copiosa fuente que produce un pie cubico de agua. Debe el exponente manifestar a V.S. que el terreno de que se habla se halla abandonado, abarrancado, y herial de inmemorial, sin más propietario que el Real Patrimonio. (...) $)^{16}$.

Todos los solicitantes, incluidos el Prior de San Agustín de Alicante y el Marqués de Peñacerrada, regaban con anterioridad sus tierras con agua de la fuente de los Baños, con la que comunicaba la descubierta. Da idea de la tensión existente entre los marqueses y la bailía y la ciudad de Alicante el hecho de que a los primeros no les fuera notificada la realización de estas diligencias en una zona comprendida en el término de Aguas.

Así se desprende del auto dictado por el juez administrador de la Bailía de Alicante, D. Manuel Sorribas, quien, al ordenar el reconocimiento, fiteo y justiprecio del terreno a los peritos, exige que «rindan Declaración con citación de los vecinos confinantes a la tierra y aguas, y respecto á que los Síndicos Procurador General y Personero de este Caserío lo son dos de la citada Ciudad de Alicante en atención á corresponder la jurisdicción á aquellos el precente Esscribano lo verificará a su regreso, evitándose por ahora la del Ylustre Marqués del Bosque Supuesto Señor Territorial hasta instruir el Expediente con la Declaración que se manda $(. ..) \gg^{17}$.

Los peritos enviados reconocieron la zona como de realengo, juzgando el establecimiento como beneficioso para la agricultura y el incremento de las rentas del Real Patrimonio, y sin ninguna incidencia negativa en relación al aprovechamiento de los pastos, montes y leñas ${ }^{18}$; sin embargo, D. Gil Mariano Pascual de Riquelme y Vergara, Marqués de Peñacerrada, señalaba, en su respuesta a la notificación, que el terreno y la fuente objeto de establecimiento eran en realidad propiedad de los Marqueses del Bosch ${ }^{19}$.

A tenor de esta declaración, se proclamaba el siguiente auto el 7-XII-1819: «Resultando por la notificación hecha al Marques de Peñacerrada que se supone Dueña de ese terreno a la Marquesa del Bosque, ignorándose tal circunstancia, tanto porque en el termino de Aguas, es Dueño directo el Real Patrimonio de muchas de las fincas que dicha Señora posee en dominio útil, como por ignorarse tambien en esta Admistración en favor de aquella tal derecho; hágasele saber á la misma (...) sin perjuicio de los que legítimamente corresponden al Real Patrimonio, sin que se considere por este hecho como Señora Territorial, á menos no lo acredite documentalmente ante Tribunal Competente que si creyese asistirla aquel, lo dedusca en el del Señor Bayle General de este Reyno, (...) ${ }^{20}$.

16 ARV. Bailía, E, n. ํ50 500, Apéndice, año 1819, fs. 1-1 vto.

17 Auto de fecha 30-VII-1819. Ibídem, fs. 10 vto.-11.

18 Ibídem, fs. 8-9 vto.

19 Ibídem, f. 10.

20 Ibídem, fs. 10 v to.-11. 
La marquesa consiguió también esta vez, presentando de nuevo como prueba el decreto de amparo de 12-VII-1816, sentencia favorable de la Real Audiencia. Así, el 29-X-1819 eran anulados por esta institución los establecimientos otorgados por el administrador de la Bailía de Alicante. A este respecto, cabe señalar como, en los casos en que el establecimiento de aguas subterráneas requería la perforación en un terreno propiedad de un tercero, el Real Patrimonio paralizaba los trámites de producirse la oposición de este último ${ }^{21}$. En este caso, sin embargo, no se pone solamente en duda la pertenencia o no de ese paraje a la Marquesa, sino también su derecho a las aguas subterráneas, y, por ende, su capacidad para establecerlas enfitéuticamente. Aunque el expediente parece quedar inconcluso, puesto que la subsiguiente protesta del administrador de la bailía de Alicante no tuvo ninguna respuesta, lo cierto es que, con posterioridad, aparece como propiedad de los marqueses del Bosque y destinada al abastecimiento de los Baños una fuente conocida como la Cogolla ${ }^{22}$.

\section{La propiedad señorial del agua. El proceso de adquisición del dominio útil de las aguas}

Como ha sido señalado con anterioridad, los titulares del señorío solariego poseían el dominio directo del agua de la mayor parte de las resurgencias del término, a la vez que se habían reservado en plena propiedad una parte de las mismas. En este sentido, en la inscripción registral del establecimiento de los Baños se declaran como de uso y disfrute para el servicio de los mismos las fuentes o manantiales de San Ignacio (antes Colladet) y de los Baños, y para la bebida el manantial de la Cogolla: «El primero y el último de dichos manantiales pertenecen en su totalidad y absoluto dominio a la citada testamentaria (del Conde de Casas Rojas, D. José de Rojas y Canicia), y el de los Baños, después de utilizarlo para éstos, lo sobrante para el riego es dueño de 49 horas en cada tanda (no fijos los días) siendo o teniendo en las demas horas de agua del mismo la señoría directa» ${ }^{23}$.

Al margen de estos recursos mencionados, el Marqués del Bosque poseía el dominio directo de gran parte de las aguas de las fuentes y balsas del lugar. Tratando de consolidar ambos dominios y conseguir de este modo la plena propiedad de las mismas, D. José de Rojas y Canicia llevará a cabo, durante toda la segunda mitad del siglo XIX, una política de adquisición del dominio útil del agua de riego; política paralela a la que desarrollará en relación a la tierra. Este proceso de adquisición está motivado por la importancia que reviste este recurso para garantizar las producciones agrícolas, dada la precariedad e irregularidad de las precipitaciones. Sin embargo, hay que matizar que la puesta en «regadío» afecta solamente a pequeñas parcelas, inferiores generalmente a una hectárea (y con frecuencia muy alejadas de esa superficie), a tenor de los escasos recursos disponibles y las condiciones físicas de este espacio.

D. José de Rojas y Canicia había adquirido entre 1847 y 1888 un total de 963 horas 33 minutos de agua, distribuidas del siguiente modo ${ }^{24}$ :

- Balsa Nueva: 306 h. 3 m. (79,70\% de la tanda).

- Balsa del Ciscar: 168 h. $(43,75 \%$ de la tanda).

21 ALBEROLA ROMA, A. (1983): Op. Cit., p. 102.

22 Registro de la Propiedad de Jijona, T. 276, Fca. 885 , fs. 174-179 vto.

23 Ibídem, f. 174.

24 El total de las horas de agua adquiridas ascendía a 957 h. $33 \mathrm{~m}$. El resultado expresado representa la cantidad final de agua propiedad del Marqués, tras la permuta realizada de 12 horas de la balsa de los Baños por 18 horas de la balsa Nueva. 
- Balsa de los Campellos: 12 h. (3,33\% de la tanda).

- Balsa del Cañar: 62 h. 30 m. (17,36 \% de la tanda).

- Balsa de los Baños: 73 h. (16,44\% de la tanda $)^{25}$.

- Balsa de los Yborras: 24 h. (5,55 \% de la tanda).

- Balsa de los Gils: 24 h.

- Balsa del Horno de Vidrio: 288 h.

Este proceso de adquisición del dominio útil del agua y la tierra en el lugar de Aguas fue continuado posteriormente por D. José de Rojas y Galiano, heredero del patrimonio vinculado de su antecesor radicado en Aguas; quien compró, a su vez, un total de 663 horas de agua 27 minutos durante el período comprendido entre 1892 y 1907 . Su distribución es la siguiente ${ }^{26}$ :

- Balsa Nueva: 58 h. 27 m. (15,22\% de la tanda).

- Balsa de los Baños: 106 h. (23,87 \% de la tanda).

- Balsa del Cantal del Paller: 31 h. $(8,61 \%$ de la tanda).

- Balsa de la Mata: 288 h. $(66,67 \%$ de la tanda).

- Balsa del Ciscar: 180 h. (46,87\% de la tanda).

El estudio de las condiciones de venta del agua (precio, gravámenes, deducciones, ...) presenta diversas dificultades. En primer lugar, las referencias localizadas en los libros de la Contaduría de Hipotecas y del Registro de la Propiedad y en los protocolos notariales no son siempre completas; $y$, en segundo lugar, al producirse frecuentemente la venta conjunta de tierra y agua, estas fuentes recogen los datos globales de la misma.

En un principio, estas adquisiciones fueron realizadas en condiciones muy ventajosas por los titulares del señorío solariego, puesto que del precio estipulado solían deducirse el importe del luismo, la cantidad satisfecha por la concesión de licencia señorial, y los capitales de censo que gravaban la finca. Rentas éstas que el Marqués había dejado de percibir o percibía con grandes dificultades, ante el rechazo de los enfiteutas a reconocer los derechos señoriales y satisfacer las pensiones derivadas de los mismos. Las fuentes utilizadas evidencian como con motivo de las ventas al Marqués se reconoce la señoría directa, cuando en las inscripciones precedentes de las fincas en el registro, en las anotaciones de los libros de la contaduría o en los títulos presentados para la inscripción registral se declaran las fincas libres de cargas. También recogen como el agua procedente de una determinada balsa en unas ocasiones se declara libre de cargas y en otras gravada (ejemplo Balsa del Ciscar).

Por lo que respecta a las cargas (que desaparecen al producirse la consolidación de dominios), generalmente no suele expresarse la cuantía de los censos, ni especificarse su carácter. Cuando éste se detalla, el enfitéutico suele responder al agua vendida independientemente de la tierra; y en las ocasiones en que se declara uno redimible (acompañando o no al enfitéutico) la transacción ha afectado a la tierra y al agua conjuntamente.

A partir de los años setenta, y con mayor frecuencia durante la década de los ochenta, el marqués recurre a la condonación del derecho de luismo y de la licencia, y, en menor medida, a la de las pensiones atrasadas y los capitales de censo, tal vez como incentivo a

25 Esas 73 junto a las 49 vinculadas al Balneario representan el 27,48\% de la tanda.

26 En conjunto, el Marqués del Bosque habría entrado en posesión de unas 1.567 horas de agua 36 minutos (al margen de las destinadas al balneario) según el Registro de la Propiedad; de las cuales 904 h. 9 m. procederían de la herencia de su padre D. José de Rojas y Canicia (cantidad que sin embargo no coincide con la señalada anteriormente en manos de este último, tal vez debido a un posible proceso de venta). 
las ventas, y ante la imposibilidad de su cobro, en unos momentos en que habrían podido prescribir ya todos los derechos de este tipo.

El interés del titular del dominio directo por obtener el útil y consolidar la plena propiedad tanto en lo referente al agua como a la tierra, se hace evidente en el proceso seguido para efectuar alguna compra. Así, en este sentido, se ha podido verificar el empleo del tanteo y el retracto en varios casos en los que había instado demanda ejecutiva por impago de deudas (generalmente previa adquisición a otros acreedores de los créditos hipotecarios impuestos sobre las fincas). En estas ocasiones, el marqués, sin efectuar ningún desembolso, además de lograr la plena propiedad, conseguía cobrar el derecho de luismo, las pensiones vencidas, los capitales de censo impuestos, y la deuda y sus intereses correspondientes $^{27}$. También se han dado ejemplos en los que, a pesar de suponer la venta una cesión en pago de las deudas contraídas a favor del marqués, se produce la condonación del luismo y otros derechos señoriales ${ }^{28}$.

Otro aspecto a señalar es la gran diferencia existente entre los precios de venta estipulados por hora de agua según la procedencia de la misma y el caudal de las diversas fuentes. Así, frente a cantidades próximas a las 4 pts./hora (16 rs./hora) en el caso de la fuente del Ciscar, a principios de la década de los cincuenta, se exigían, en fechas similares, cantidades bastante superiores a las 50 pts./hora ( 200 rs./hora) en el de las balsas Nueva y de los Baños. Se observa en general una tendencia ascendente de los precios del agua procedente de los diferentes manantiales hasta finales de la década de los ochenta y principios de la de los noventa, momento en que comienzan a experimentar un descenso; aunque hay que señalar la oscilación existente de un año a otro ${ }^{29}$. La hora de agua más cotizada, hasta la década de los noventa (aunque teniendo en cuenta que desconocemos las diferencias de caudal existentes entre las diversas fuentes del término), es la correspondiente a la balsa de los Baños (73,96 pts./hora -295 rs./h.— en 1854; 125 pts./h. - 500 rs./h.- en 1886; 100 115 pts./h. en 1898-1899; o 90 pts./h. en 1907); puesto que a partir de esta fecha disminuyen la mayor parte de los precios (40 pts./h. de la balsa Nueva en 1892, cuando en 1849 se había situado en 62,50 o en 1872 en 78,90 pts./h.) exceptuando los fijados para el agua procedente de la balsa del Cantal del Paller, cuyas horas de agua siguen incrementando su valor ( $250 \mathrm{pts} . / \mathrm{h}$. establecidas en 1898, frente a las 150 de 1891 o las 200 de 1897). Una evolución similar presenta la balsa de la Mata, aunque con valores mucho más reducidos (20,83 pts./h. en $1892 ; 31,25$ pts./h. en 1899).

Estos bienes, a pesar de su paulatina pérdida de valor (tanto por la desecación de la mayor parte de las fuentes - así ha sido puesto de manifiesto en páginas anteriores- como por el abandono de la actividad agrícola) fueron pasando de unos herederos a otros hasta la última Marquesa del Bosch, D. - Teresa de Rojas y Roca de Togores, quien las donó en su gran mayoría a sus tres hijas, por iguales terceras partes proindiviso. El interés por mantener la propiedad de este recurso refleja la gran importancia que adquiere en esos momentos.

27 Por ejemplo, con motivo de la adquisición de 29,5 horas de agua de la balsa del Cañar (junto con una parcela de tierra), a M. y T. Méndez en 15-VIII-1879. Registro de la Propiedad de Jijona. Fca. 44, Tomo 8, Lib. 1 Aguas, fs. 137-142; T. 143, Lib. 7 Aguas, fs. 2-5 vto y T. 154, Lib. 8 Aguas, fs. 240-244 vto. Un caso similar es el de la compra a los herederos de L. Arnáu Yborra de 24 horas de la balsa de los Yborras (o del Gasparet) en 26-XI-1879. Ibídem, Fca. 678, T. 174, fs. 192-196 vto.

28 Así sucedía con la venta, de 24 horas de agua de la balsa de los Baños, efectuada por F. y A. Giner Yborra el 14-VII-1892. Así se pone de manifiesto en el siguiente testimonio recogido en una anotación registral: «El Excelentísimo Señor D. José de Rojas y Galiano en concepto de Marqués del Bosch inscribe su título de compra-venta del dominio útil de la finca de este número, y renuncia al cobro de los derechos que como tal Marqués, podría reclamar de los vendedores por luismo y demás; cuya renuncia hace en concepto de Marqués del Bosch». Ibídem, Fca. 857, T. 276, fs. $184-186$ vto.

29 El caso más evidente son los 1.500 rs. (375 pts.) pagados por una hora de agua de la balsa de los Baños en 1881 , cuando ese mismo año se habían pagado $266^{\prime} 67$ rs. (66'67 pts.) por la hora de agua de esa procedencia. 